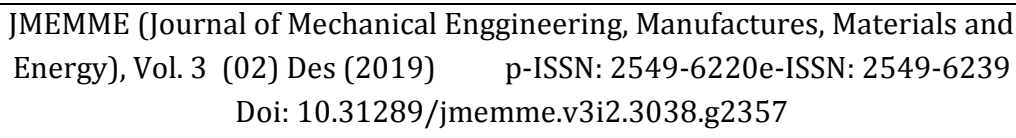

JMEMME (Journal of Mechanical Engineering, Manufactures, Materials and Energy)

\title{
RANCANGAN PENYIMPAN BUAH DAN SAYURAN MENGGUNAKAN SISTEM PENDINGINAN PASIF/EVAPORATIF
}

\author{
Fazri Amir*, Zainal Arif, Ponidi Sanjaya, Syamsul Bahri Widodo \\ Program Studi Teknik Mesin, Universitas Samudra \\ Diterima: 01-11-2019 ; Disetujui: 05-12-2019 ; Diterbitkan: 30-12-2019 \\ *Corresponding author: fazri@unsam.ac.id
}

\begin{abstract}
Abstrak
Pembusukan buah dan sayuran dapat terjadi disebabkan kurangnya fasilitas penyimpanan yang tepat. Solusi terbaiknya adalah disimpan pada toko buah dan sayuran yang menyediakan sistem pendinginan yang komplit seperti yang ada di mall-mall kota besar, sedangkan petani-petani dan pedagangan pedangang khususnya di daerah pedesaan tidak memiliki modal yang cukup untuk membuat sistem pendingin yang memadai. Tujuan dari penelitian ini adalah membuat dan merancang suatu teknologi sederhana tempat penyimpan buah dan sayuran agar tetap segar selama waktu tertentu menggunakan sistem pendinginan pasif. Metodologi Proses desain dan pembuatan alat ini menggunakan sampel sistem penyimpanan dingin buah dan sayuran segar menggunakan sistem pendinginan pasif. Pipa dan lembaran aluminium persegi panjang berongga diukur, dipotong dan dirakit untuk membentuk persegi panjang untuk ruang penyimpanan dengan sisi kiri dibiarkan terbuka untuk penyisipan pad goni dan kawat mesh sesuai dengan spesifikasi desain. Dari hasil pengujian diperoleh bahwa alat ini dapat enjaga suhu ruang pendinginan evaporatif mencapai temperatur $22^{\circ} \mathrm{C}$, dan diteliti selama 10 hari. alat ini sangat baik digunakan sebagai tempat penyimpanan buah dan sayuran yang dapat memperpanjang umur penyimpanan.
\end{abstract}

Kata Kunci : Rancangan Penyimpangan Buah dan Sayur, Sistem Pendinginan Masif, Masa Waktu Penyimpanan

\section{Abstract}

Fruit and vegetable spoilage can occur due to lack of proper storage facilities. The best solution is to store it in fruit and vegetable stores that provide a complete cooling system like those in big city malls, while farmers and traders - especially in rural areas do not have enough capital to make an adequate cooling system. The purpose of this research is to create and design a simple technology for storing fruits and vegetables to stay fresh for a certain time using a passive cooling system. Methodology The process of design and manufacture of this tool uses a sample cold storage system of fresh fruits and vegetables using a passive cooling system. Rectangular hollow aluminum pipes and sheets are measured, cut and assembled to form a rectangle for storage space with the left side left open for insertion of the burlap pad and wire mesh according to design specifications. From the test results obtained that this tool can keep the evaporative cooling chamber temperature reaching $22^{\circ} \mathrm{C}$, and studied for 10 days. This tool is very well used as a storage place for fruits and vegetables that can extend the storage life

Keywords: Design of Fruit and Vegetable Deviations, Massive Cooling System, Storage Period

How to Cite: Amir, F., 2019, Rancangan Penyimpan Buah dan Sayuran Menggunakan Sistem Pendinginan Pasif/Evaporatif. JMEMME (Journal of Mechanical Enggineering, Manufactures, Materials and Energy), 3(02): 117-122 
Amir, F., Rancangan Penyimpan Buah dan Sayuran Menggunakan Sistem ...

\section{PENDAHULUAN}

Pendinginan evaporatif adalah teknik pendinginan yang menggunakan penguapan air sehingga temperatur suatu zat akan berkurang [1-3]. Saat terjadi Perubahan fasa dari sensible (cair) ke laten (penguapan) menyebabkan terjadinya penurunan suhu sekeliling dan menghasilkan dingin. Efek dari pendinginan tersebut dapat dimanfaatkan untuk mendinginkan ruangan yang kecil. Ruangan kecil ini dapat dijadikan sampel suatu wadah tertentu yang dapat dimanfaatkan sesuai dengan kebutuhan. Salah satu aplikasinya dapat digunakan sebagai wadah pendinginan buah-buahan dan sayur-sayuran [2, 4-6].

Buah-buahan dan sayuran-sayuran dari hasil panen akan mengalami pembusukan terlalu dini jika tidak disimpan diruang yang dikondisikan. Oleh karena itu dengan menggunakan konsep pendinginan evaporatis dapat memperpanjang umur simpan buahanbuahan dan sayur-sayuran. Untuk menjaga kualitas buah dan sayuran yang disimpan, biasanya disimpan dalam kondisi lembab [3]. Untuk sebagian besar buahan-buahan dan sayur-sayuran yang mudah busuk, semakin tinggi kelembabannya semakin baik dalam penyimpanan. Namun jika kelembabannya juga tinggi, air dapat mengembun di atas buah dan sayuran menyebabkan meningkatnya pembusukan [7]. Oleh karena itu Kerusakan sayur dan buah segar (Lycopersicon esculentum) selama penyimpanan sebagian tergantung pada suhu [4]. Menurut [2], menyatakan bahwa menjaga produk pada tingkat terendah sangat aman pada suhu $0{ }^{\circ} \mathrm{C}$ untuk tanaman sedang atau $10-12{ }^{\circ} \mathrm{C}$ untuk mendinginkan tanaman yang sensitif.

Pembusukan buah dan sayuran yang terjadi saat ini disebabkan kurangnya fasilitas penyimpanan yang tepat. Solusi terbaiknya adalah disimpan pada toko buah dan sayuran yang menyediakan sistem pendinginan yang komplit seperti yang ada di mall-mall kota besar, cara ini tentunya membutuhkan biaya yang mahal. Sementara petani-petani dan pedagangan - pedangang khususnya di daerah-daerah tidak memiliki modal yang cukup untuk membuat sistem pendingin yang komplit tersebut $[8,9]$.

Proses perubahan dari cair menjadi uap, energi sangat diperlukan. Adapun energi yang dimaksud adalah energi panas. Energi yang ditambahkan ke air untuk mengubahnya menjadi uap berasal dari lingkungan, sehingga membuat lingkungan lebih dingin [10].

Suhu Udara yang dimaksudkan adalah penguapan terjadi bila air menyerap cukup energi untuk terjadinya perubah dari cair ke gas. Udara pada suhu tinggi mampu merangsang terjadinya proses evaporasi dan juga mampu menyerap uap air dalam jumlah besar. Oleh karena itu, kondisi pada suhu tinggi akan memiliki tingkat penguapan yang tinggi dan pendinginan terjadi relative lebih banyak. Dan sebaliknya, jika suhu lebih rendah, maka uap air lebih sedikit yang dapat diserap dan penguapan yang terjadi lebih sedikit sehingga terjadi pendinginan akan terjadi [11]. 
Kelembaban Relatif Udara adalah pengukuran jumlah uap air di udara sebagai persentase dari jumlah maksimum yang udara mampu menahan pada suhu tertentu. Jika kelembaban relatif udara rendah, berarti hanya sebagian dari jumlah total air yang ada di udara yang mampu diserap. Dalam kondisi ini, udara mampu mengambil kelembaban tambahan, oleh sebab itu dengan semua kondisi lain yang sangat menguntungkan, tingkat penguapan akan lebih tinggi, dan dengan demikian efisiensi pendinginan penguapan sistem diharapkan lebih tinggi [10].

Anyanwu (2014) telah melakukan desain, konstruksi dan mengukur kinerja pendingin penguapan berpori untuk pelestarian buah-buahan dan sayuran. Eksperimental lebih dingin, dengan total ruang penyimpanan 0,014 m3. Desain konstruksi yang terdiri dari sebuah wadah tanah liat berpori berbentuk kubus yang terletak di dalam wadah lain wadah tanah liat. Diantara wadah tersebut ditambahkan serat kelapa. Tempat penampungan air yang terhubung ke pendingin di bagian atas melalui pipa yang fleksibel memasok air untuk mengisi celah, dengan demikian menjaga serat kelapa terus basah. Hasil dari tes kinerja sementara mengungkapkan bahwa penyimpanan pendingin Depresi suhu ruang dari suhu udara sekitar bervariasi antara 0,1-12 C. Suhu udara sekitar selama periode pengujian berkisar antara $22-38{ }^{\circ} \mathrm{C}$. dari hasil pengujian juga mengilustrasikan kinerja pendingin lebih unggul daripada pengawetan udara terbuka. Kondisi sayuran segar selama operasi dinorrnalkan. Dengan demikian, pendingin evaporatif memiliki prospek untuk digunakan untuk pengawetan sayuran jangka pendek dan buah-buahan segera setelah panen [12].

Thiagu dan kawa-kawan (2007) telah melakukan penelitian dengan membandingkan tomat yang matang kondisi penyimpanan pendinginan atau evaporative cooling (EC) $\left(20^{\circ} \mathrm{C}-25^{\circ} \mathrm{C}\right.$, 92 - 95\% RH) dengan buah kontrol disimpan di bawah ruangan kondisi (28 $\left.{ }^{\circ} \mathrm{C}-33{ }^{\circ} \mathrm{C}, 45-65 \% \mathrm{RH}\right)$. Hasil yang diperoleh adalah menunjukkan buah yang disimpan EC menunjukkan nilai yang lebih rendah untuk tekanan pecah dan geser. Tingkat kehilangan kelembaban untuk buah kontrol adalah 6,5 kali lebih besar dari EC yang disimpan tomat [10]

Berdasarkan analisa diatas, penenelitian ini akan membuat dan merangcang suatu teknologi sederhana tempat penyimpan buah dan sayuran dengan agar tetap segar selama waktu tertentu menggunakan sistem pendinginan pasif.

\section{METODE PENELITIAN}

Penelitian ini merancang dan membuat sebuah alat penyimpanan buah segar dengan menggunakan suatu teknologi sederhana yang digunakan untuk tempat penyimpan buah dan sayuran agar tetap segar selama waktu tertentu menggunakan sistem pendinginan pasif. Dengan alat sederhana ini dapat menyimpan buah dan sayuran sehigga dapat menjaga buah dan sayuran agar tetap segar. Adapun rancangan desain alat dapat dilihat pada Gambar 1 sampai dengan Gambar 3. 
Untuk data rancangan desain alat dapat diperoleh pada tabel 1 .

Tabel 1 Spesifiaksi data rancangan

\begin{tabular}{|l|l|l|}
\hline No & \multicolumn{1}{|c|}{$\begin{array}{c}\text { Spesifikasi Data } \\
\text { Rancangan }\end{array}$} & \multicolumn{1}{c|}{ Ukuran } \\
\hline 1 & Sisi depan dan belakang & $0,8 \times 0,2 \mathrm{~m}$ \\
\hline 2 & sisi kiri dan kanan & $0,8 \times 0,5 \mathrm{~m}$ \\
\hline 3 & sisi atas & $0,5 \times 0,4 \mathrm{~m}$ \\
\hline 4 & dudukan reservoir & $0,5 \times 0,3 \mathrm{~m}$ \\
\hline 5 & volume sistem penyimpanan & $0,4 \times 0,5 \times 0,8 \mathrm{~m}$ \\
\hline 6 & volume reservoir & $3,14 \times 0,162 \times 0,3 \mathrm{~m}$ \\
\hline 7 & $\begin{array}{l}\text { Pemilihan ukuran exhaust } \\
\text { fan }\end{array}$ & $19,6 \mathrm{~cm}$ \\
\hline 8 & Panel surya & $18 \mathrm{~V}, 0,36 \mathrm{~A}$ \\
\hline 9 & Baterai & $12 \mathrm{~V}, 6 \mathrm{AH}$ \\
\hline
\end{tabular}

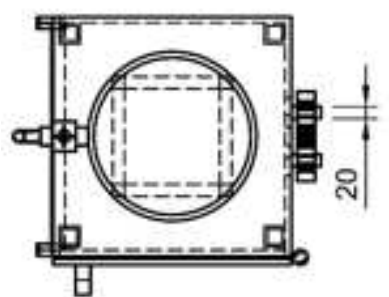

Gambar 1. Tampak atas rancangan alat

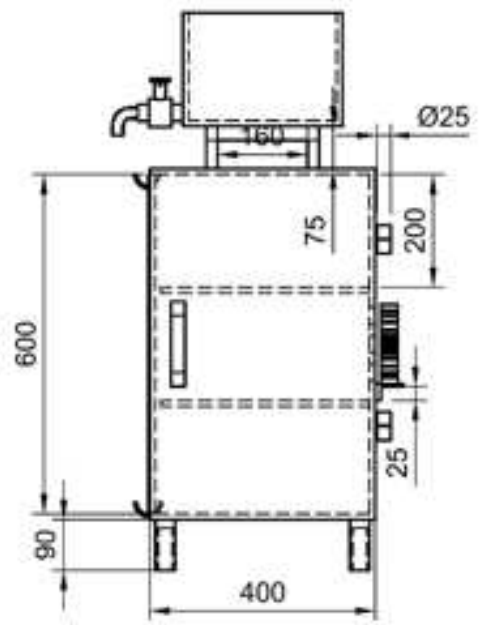

Gambar 2. Tampak depan rancangan alat

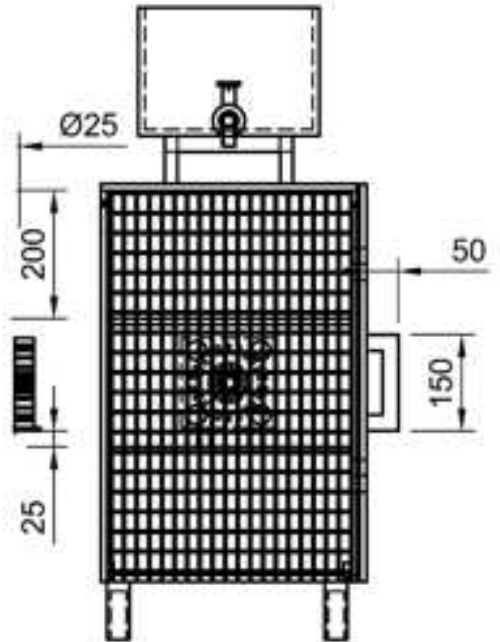

Gambar 3. Tampak samping pada pendingin evaporative

Proses desain dan pembuatan alat ini menggunakan sebagai sampel sistem penyimpanan dingin buah dan sayuran segar dimulai dengan mengukur Pipa dan lembaran aluminium persegi panjang berongga, lalu dipotong dan dirakit untuk membentuk persegi panjang. Ruang penyimpanan didisain dengan sisi kiri dibiarkan terbuka. Pada sisi ini sisipkan pad goni dan kawat mesh sesuai dengan spesifikasi desain. Pipa dan lembaran itu dirakit dengan bantuan sekrup. Tiga bukaan melingkar didisan dengan radius $60 \mathrm{~mm}$ dibuat di sisi berlawanan dengan pad goni di mana exhuase fan dipasang. Ruang penyimpanan dibagi menjadi dua rak menggunakan kawat mesh. Pembukaan $10 \mathrm{~mm}$ radius dibuat di dekat bagian bawah tangki reservoir yang memiliki volume 24 liter. Pipa PVC $20 \mathrm{~mm}$ diameter dimasukkan dalam pembukaan, T-sendi, dan sendi siku digunakan untuk menghubungkan jaringan pipa bersama menggunakan permen karet untuk menahan pipa pada posisi dan sebuah sumbat juga digunakan pada ujung jaringan pipa 
untuk menghentikan aliran air. Pipa-pipa itu dipasang sehingga satu pipa melindas area pad goni, benda tajam digunakan untuk melubangi pipa pada interval tertentu menciptakan bukaan jadi air mengalir di atas bantalan goni saat katup kontrol dibuka. Pipa PVC berdiameter 40 $\mathrm{mm}$ dibagi menjadi dua bagian dengan setengah terhubung di bagian bawah sistem penyimpanan di samping adalah bantalan goni dimasukkan sehingga mengumpulkan air berlebih yang menetes dari pad goni.

\section{HASIL DAN PEMBAHASAN}

Hasil Rancangan dan pembuatan alat teknologi sederhana tempat penyimpan buah dan sayuran agar tetap segar selama waktu tertentu menggunakan sistem pendinginan pasif dapat dilihat pada Gambar 4

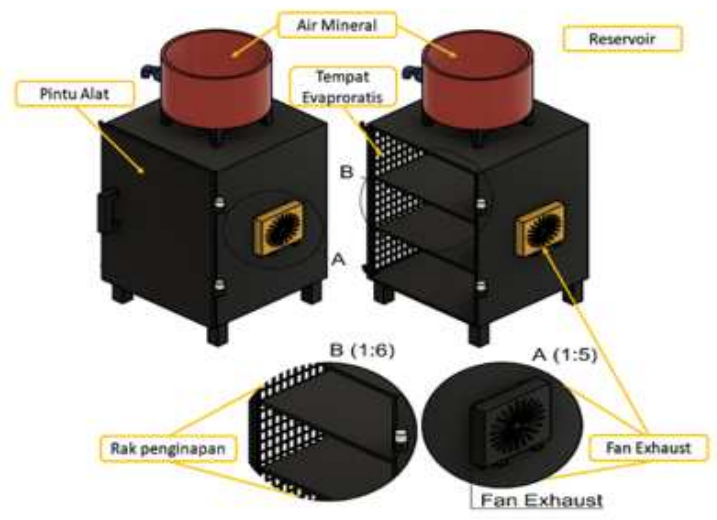

Gambar 4. Alat sederhana Penyimpan Buah

Desain sistem penguapan didasarkan pada prinsip penguapan selalu disertai oleh efek pendinginan ke sekitarnya. Alat tersebut merupakan sistem tertutup yang terdiri dari empat (4) sisi, sehingga satu (1) sisi terbuat dari kawat mesh dan pad (bahan goni), sementara tiga sisi sisanya terbuat dari lembaran aluminium di mana sisi yang berlawanan dengan bagian pad goni adalah dilengkapi dengan tiga kipas hisap dengan jarak yang baik. Udara diizinkan melewati pad ke dalam sistem dengan bantuan penggemar isap. Air menetes ke pad goni dengan laju konstan melalui sistem distribusi air. Sebagian Air menetes ke bantalan kipas hisap menarik udara hangat dari sistem dan membagikannya. Selama proses ini udara hangat yang merupakan panas sensibel melewati pad basah yang sekarang diubah menjadi panas laten karena penguapan yang telah terjadi sebagai akibat dari keberadaan air menguap yang menyebabkan pendinginan di dalam selungkup untuk mencapai perbedaan suhu lingkungan, sebagai hasil dari ini, umur simpan sayuran diharapkan meningkat.

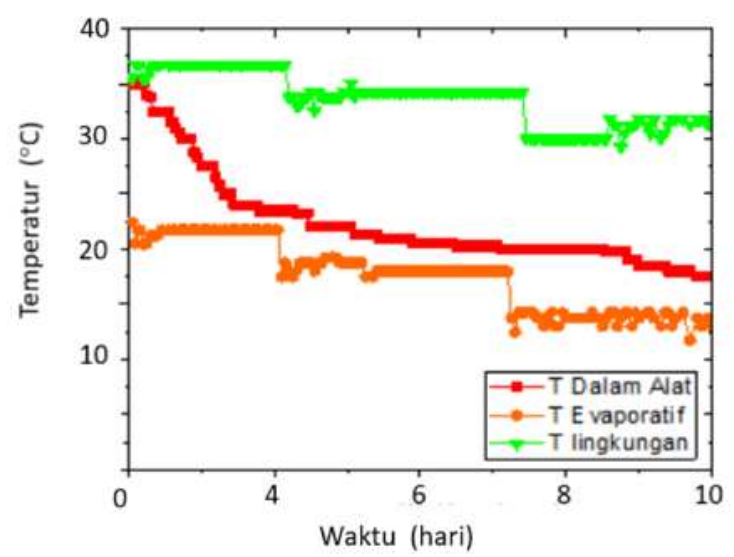

Gambar 5. Grafik Temperatur pada evaproratif

Dari pengujian alat ini diperoleh grafik hasil pengukuran temperatur terhadap waktu selama 10 hari dapat dijelaskan seperti ditunjukkan pada Gambar 5. Dari grafik dapat dilihat bahwa suhu lingkungan pada saat pengujian berkisar antara suhu $32^{\circ} \mathrm{C}$ sampai dibawah temperatur $36^{\circ} \mathrm{C}$. Untuk temperatur evaporatif awal alat bekerja dari temperatur $24^{\circ} \mathrm{C}$ turun menjadi 
Amir, F., Rancangan Penyimpan Buah dan Sayuran Menggunakan Sistem ...

suhu sekitar $\quad 15^{\circ} \mathrm{C}$. sedangkan Temperatur dalam ruang alat terjadi penurunan temperatur yang sangat signifikan, dari temperatur $35^{\circ} \mathrm{C}$ turun ke temperatur $22^{\circ} \mathrm{C}$.

\section{KESIMPULAN}

Perancangan dan pembuatan suatu alat teknologi sederhana tempat penyimpan buah dan sayuran telah berhasil dibuat dengan menggunakan system pendingin pasif (Evaporated cooling). Tempat ini sangat baik digunakan sebagai tempat penyimpanan buah dan sayuran yang dapat memperpanjang umur simpan buah dan sayuran agar tetap segar. Dari hasil pengujian didapatkan bahwa kondisi temperatur dapat diturunkan menjadi suhu kamar $22^{\circ} \mathrm{C}$. Sehingga dengan kondisi temparatur ini dapat membuat buah dan sayuran tetap segar.

\section{PENGHARGAAN}

Penghargaan disampaikan sebesarbesarnya kepada LPPM-PM Universitas Samudra atas bantuan dana penelitian

\section{REFERENCES}

[1] S. M. Dadhich, H. Dadhich, and R. Verma, "Comparative Study on Storage of Fruits and Vegetables in Evaporative Cool Chamber and in Ambient," Int. J. Food Eng., vol. 4, no. 1, Jan. 2008.

[2] M. Sushmita, D. Hemant, and V. Radhacharan, "Vegetables in evaporative cool chamber and in ambient," 2008.

[3] S. Olushola, J. Olanrewaju, O. Adeola, and A. Olaoluwa, "Comparative analysis of cooling efficiencies and nutritional variations of two different types of evaporative cooling," 2012.

[4] E. Lucas, "Modification and Testing of An Evaporative Cooling Facility for Storing Vegetables," 2011.
[5] B. Yunianto and N. E. Isnandi, "Pengaruh Jenis Sprayer Terhadap Efektivitas Pendinginan Evaporasi Kontak Langsung," ROTASI, vol. 19, no. 3, p. 110, Sep. 2017.

[6] B. S. T. Silalahi, T. A. Ajiwiguna, and M. R. Kirom, "Studi Pendingin Evaporatif Untuk Pendinginan Air," eProceedings Eng., vol. 5, no. 3, Dec. 2018.

[7] A. Thompson, "Onion storage in tropics," WHURR Publ. LTD 19B ..., 1970.

[8] N. Asiah, L. Cempaka, and W. David, "Panduan Praktis Pendugaan Umur Simpan Produk Pangan," 2018.

[9] T. Sutanto, "Rahasia Sukses Budidaya Tanaman Dengan Metode Hidroponik," 2015.

[10] W. Nugroho, "Rancang Bangun Alat Pendingin Minuman Portable Menggunakan Peltier," 2017.

[11] "ANALISIS VARIASI DIAMETER PIPA KAPILER DOUBLE HELICAL TERHADAP PRESTASI KERJA MESIN PENDINGIN MENGGUNAKAN REFRIGERAN LPG."

[12] E. E. Anyanwu, "Design and measured performance of a porous evaporative cooler for preservation of fruits and vegetables," Energy Convers. Manag., vol. 45, no. 13-14, pp. 2187-2195, Aug. 2014. 